No anatomist has hitherto been able to distinguish these three systems of nerves by microscopic observation. But it is admitted in physiology that the only way in which the sensation excited by a particular nerve can vary is by degrees of intensity. The intensity of the sensation may vary from the faintest impression up to an insupportable pain ; but whatever be the exciting cause, the sensation will be the same when it reaches the same intensity. If this doctrine of the function of a nerve be admitted, it is legitimate to reason from the fact that colour may vary in three different ways, to the inference that these three modes of variation arise from the independent action of three different nerves or sets of nerves.

Some very remarkable observations on the sensation of colour have been made by M. Sigmund Exner in Prof. Helmholtz's physiological laboratory at Heidelberg. While looking at an intense ligbt of a brilliant colour, he exposed his eye to rapid alternations of light and darkness by waving his fingers before his eyes. Under these circumstances a peculiar minute structure made its appearance in the field of view, which many of us may have casually observed. M. Exner states that the character of this structure is different according to the colour of the light employed. When red light is used a veined structure is seen; when the light is green, the field appears covered with minute black dots, and when the light is blue, spots are seen, of a larger size than the dots in the green, and of a lighter colour.

Whether these appearances present themselves to all eyes, and whether they have for their physical cause any difference in the arrangement of the nerves of the three systems in Helmholtz's theory I cannot say, but I am sure that if these systems of nerves have a real existence, no method is more likely to demonstrate their existence than that which M. Exner has followed.

\section{Colour Blindness}

The most valuable evidence which we possess with respect to colour vision is furnished to us by the colour-blind. A considerable number of persons in every large community are unable to distinguish between certain pairs of colours which to ordinary people appear in glaring contrast. Dr. Dalton, the founder of the atomic theory of chemistry, has given us an acccount of his own case.

The true nature of this peculiarity of vision was first pointed out by Sir John Herschel in a letter written to Dalton in 1832 , but not known to the world till the publication of "Dalton's Life" by Dr. Henry. The defect consists in the absence of one of the three primary sensations of colour. Colourublind vision depends on the variable intensities of two sensations instead of three. The best description of colour-blind vision is that given by Prof. Pole in his account of his own case in the "Phil. Trans. " 1859.

In all cases which have been examined with sufficient care, the absent sensation appears to resemble that which we call red. The point $\mathrm{P}$ on the chart of the spectrum represents the relation of the absent sensation to the colours of the spectrum, deduced from observations with the colour box furnished by Prof. Pole.

If it were possibie to exhibit the colour corresponding to this point on the chart, it would be invisible, absolutely black, to Prof. Pole. As it does not lie within the range of the colours of the spectrum we cannot exhibit it; and, in fact, colour-blind people can perceive the extreme end of the spectrum which we call red, though it appears to them much darker than to us, and does not excite in them the sensation which we call red. In the diagram of the intensities of the three sensations excited by different parts of the spectrum, the upper figure, marked $P$, is deduced from the observations of Prof. Pole; whi'e the lower one, marked $K$, is founded on observations by a very accurate observer of the normal type.

The only difference between the two diagrams is that in the upper one the red curve is absent. The forms of the other two curves are nearly the same for both observers. We have great reason therefore to conclude that the colour sensations which Prof. Pole sees are what we call green and blue. This is the result of my calculations ; but Prof. Pole agrees with every other colour-blind person whom I know in denying that green is one of his sensations. The colour-blind are always making mistakes about green things and confounding them with red. The colours they have no doubts about are certainly blue and yellow, and they persist in saying that yellow, and not green, is the colour which they are able to see.

To explain this discrepancy we must remember that colourblind persons learn the names of colours by the same method as ourselves. They are told that the sky is blue, that grass is green, that gold is yellow, and that soldiers' coats are red. They observe difference in the colours of these objects, and they often suppose that they see the same colours as we do, only not so well. But if we look at the diagram we shall see that the brightest example of their second sensation in the spectrum is not in the green, but in the part which we call yellow, and which we teach them to call yellow. The figure of the spectrum below Prof. Pole's curves is intended to represent to ordinary eyes what a colour-blind person would see in the spectrum. I hardly dare to draw your attention to it, for if you were to think that any painted picture would enable you to see with other people's vision I should certainly have lectured in vain.

\section{ON THE YeLLOW SPOT}

Experiments on colour indicate very considerable differences between the vision of different persons, all of whom are of the ordinary type. A colour, for instance, which one person on comparing it with white will pronounce pinkish, another person will pronounce greenish. This difference, however, does not arise from any diversity in the nature of the colour sensations in different persons. It is exactly of the same kind as would be observed if one of the persons wore yellow spectacles. In fact, most of us have near the middle of the retina a yellow spot through which the rays must pass before they reach the sensitive organ : this spot appears yeilow because it absorbs the rays near the line $F$, which are of a greenish-blue colour. Some of us have this spot strongly developed. My own observations of the spectrum near the lins $\mathrm{F}$ are of very little value on this account. I am indebted to Professor Stokes for the knowledge of a method by which any one may see whether he has this yellow spot. It consists in looking at a white object through a solution of chloride of chromium, or at a screen on which light which has passed through this solution is thrown. This light is a mixture of red light with the light which is so strongly absorbed by the yellow spot. When it falls on the ordinary surface of the retina it is of a neutral tint, but when it falls on the yellow spot only the red light reaches the optic nerve, and we see a red spot floating like a rosy cloud over the illuminated field.

Very few persons are unable to detect the yellow spot in this way. The observer $\mathrm{K}$, whose colour equations have been used in preparing the chart of the spectrum, is one of the very few who do not see everything as it through yellow spectacles. As for myself, the position of white light in the chart of the spectrum is on the yellow side of true white even when I use the outer parts of the retina; but as soon as I look direct at it, it becomes much yellower, as is shown by the point $\mathrm{W} \mathrm{C}$. It is a curious fact that we do not see this yellow spot on every occasion, and that we do not think white objects yellow. But if we wear spectacles of any colour for some time, or if we live in a room lighted by windows all of one colour, we soon come to recognise white paper as white. This shows that it is only when some alteration takes place in our sensations that we are conscious of their quality.

There are several interesting facts about the colour sensation which I can only mention briefly. One is that the extreme parts of the retina are nearly insensible to red. If you hold a red flower and a blue flower in your hand as far back as you can see your hand, you will lose sight of the red flower, while you still see the blue one. Another is, that when the light is diminished red objects become darkened more in proportion than blue ones. The third is, that a kind of colour blindness in which blue is the absent sensation can be produced artificially by taking doses of santonine. This kind of colour blindness is described by Dr. Edmund Rose, of Berlin. It is only temporary, and does not appear to be followed by any more serious consequences than headaches. I must ask your pardon for not having undergone a course of this medicine, even for the sake of becoming able to give you information at first hand about colour-blindness.

\section{J. Clerk maxwell}

\section{SCIENTIFIC SERIALS}

THE Quarterly Fournal of Science for April commences with a very interesting account, by Dr. Hofmann, of the early days of the Royal College of Chemistry, under the title of "A Page of Scientific History." After tracing the influence of Liebig's school at Giessen on the progress of chemical science in this country, and the choice of himself, at the recommendation of Liebig, as the professor at the laboratory which it was deter- 
mined to establish in London, Dr. Hofmann proceeds to a narrative of the difficulties experienced by the new school in the deficiency of the money received from the fees of students to meet the necessary expenses as well as the debt incurred by the outlay for building. At this stage the college narrowly escaped the entire abandonment of its primary object, the advancement of science by means of practical instruction and original re$\mathrm{s}$ sarches, to sink into a mere commercial undertaking for conducting analyses. To the influence of Sir James Clark, one of the earliest friends of the College, was mainly due the ultimate sticcess of the efforts of the Council to induce the Government to adopt the College as the chemical department of the Museum of Practical Geology ; since which period its career of usefulness lias been unchecked,-Dr. A. E. Sansom follows with an article on "The Theory of Atmospheric Germs," in which he records the investigations on this subject which have been conducted to the present time, especially those of Hallier and Bastian ; and sums up adversely to the theory of abiogenesis. - Mr. Mungo Ponton, in his short paper on Molecules, Ultimates, Atoms, and Waves, suggests the use of the term "molecule" to denote the particles of chemical compounds ; "ultimate," those of chemical elements ; and "atom," the assumed constituents of those ultimates, themselves incapable of further analysis.-Prof. Piazzi Smyth occupies no less than thirty-eight pages with the conclusion of his article on "The Great Pyramid of Egypt from a modern scientific Point of View."-Sir William Fairbairn has some very practical remarks on Steam Boiler Legislation, in which he details the failure of voluntary associations for the purpose of diminishing the loss of life and property occasioned by the use of defective boilers, and advocates the enforced legal testing of boilers by competent authorities, maintaining that it is clearly the duty of the Government to interfere on behalf of those whose lives are jeopardised, and to enact that no boiler shall be worked unless periodically examined and certified. - The last article is an account of the Eclipse of last December, by Mr. R. A. Proctor. Notices of books and a record of the progress of science in the departments of light, heat, electricity, meteorology, mineralogy, mining, metallurgy, engineering, geology and palæontology, and botany, fill up a very good number.

The numbers of the American Naturalist for March and April contain some good articles. The Polarity of the Compass Plant (Silphium laciniatum) is a subject which has recently attracted attention, and Mr. W. F. Whitney's short article under this title sums up what is at present known about its causes. Mr. J. A. Allen's paper in a previous number on "The Flora of the Prairies" is followed by one on "The Fauma of the Prairies." D. G. H. Perkins describes some interesting relics of the Indians of Vermont, illustrated with woodcuts.-Mr. F. W. Vogel has an article on the Principles of Bee Breeding.-Mr. E. L. Greene gives an account of the Spring Flowers of Colorado.-Mr. W. Wood has a valuable article on the Game Falcons of New Fngland; and Dr. A. S. Packard, jun., one on Bristle-tails and Spring-tails, the Lepismas and Poduras, illustrated by plates, and containing a very full account of this interesting family. In both numbers are also reviews of recent works on natural history, and many interesting paragraphs of intelligence under the heads of botany, zoology, gewlogy, anthropology, and microscopy, original or compiled, from American and foreign sources.

\section{SOCIETIES AND ACADEMIES}

\section{LONDON}

Royal Society, April 27.- "On the Increase of Electrical Resistance in Conductors with rise of Temperature, and its application to the Measure of Ordinary and Furnace Temperatures; also on a simple Method of measuring Electrical Resistances." By C. W. Siemens, F.R.S., D.C.L.

The first part of this paper treats of the question of the ratio of increase of resistance in metallic conductors with increase of temperature.

The investigations of Arndtson, Dr. Werner Siemens, and Dr. Matthiessen are limited to the range of temperatures between the freezing and boiling-points of water, and do not comprise platinum, which is the most valuable method for constructing pyrometric instruments.

Several series of observations are given on different metals, including platinum, copper, and iron, ranging from the freezingoint to $350^{\circ}$ Cent, ; another set of experiments being also given, extending the observations to rooo? Cent. These results are planned on a diagram, showing a ratio of increase which does not agree either with the former assumption of a uniform progression, or with Dr. Matthiessen's formula, except between the narrow limits of his actual observations, but which conforms itself to a parabolic ratio, modified by two other coefficients, representing linear expansion and an ultimate minimum resistance.

In assuming a dynamical law, according to which the electrical resistance of a conductor increases according to the velocity with which the atoms are moved by heat, a parabolic ratio of increase of resistance with increase of temperature follows; and in adding to this the coefficients just menitioned, the resistance $r$ for any temperature is expressed by the general formula,

$$
r=\alpha T^{\frac{1}{2}}+\beta T+\gamma,
$$

which is found to agree very closely both with the experimental data at low temperatures supplied by $\mathrm{D}_{\mathrm{r}}$. Matthiessen, and with the author's experimental results, ranging up to $1000^{\circ}$ Cent. He admits, however, that further researches will be necessary to prove the applicability of the law of increase expressed by this formula to conductors generally.

In the second part of this paper it is shown that, in taking advantage of the circumstance that the electrical resistance of a metallic conductor increases with an increase of temperature, an instrument may be devised for measuring with great accuracy the temperature at distant or inaccessible piaces, including the interior of furnaces, where metallurgical or other smelting operations are carried on.

In measuring temperatures not exceeding $100^{\circ}$ Cent., the instrument is so arranged that two similar coils are connected by a light cable containing three insulated wires. One of these coils, "the thermometer-coil," being carefully protected against moisture, may be lowered into the sea, or buried in the ground, or fixed at any elevated or inaccessible place whose temperature has to be recorded from time to time ; while the other, or "com. parison-coil," is plunged into a test-bath, whose temperature is raised or lowered by the addition of hot or cold water, or of refrigerated solutions, until an electrical balance is established between the resistances of the two coils, as indicated by a galva. noscope, or by a differential voltameter, described in the second paper, which balance implies an identity of temperature at the two coils. The temperature of the test-solution is thereupon meastred by means of a delicate mercury thermometer, which at the same time tells the temperature at the distant place.

By another arrangement the comparison-coil is dispensed with, and the resistance of the thermometer-coil, which is a known quantity at zero temperature, is measured by a differential voltameter, which forms the subject of the second paper; and the temperature corresponding to the indications of the instrument is found in a table, prepared for this purpose, in order to save all calculation.

In measuring furnace temperatures the platinum-wire constituting the pyrometer is wound upon a small cylinder of porcelain contained in a closed tube of iron or platinum, which is exposed to the heat to be measured. If the heat does not exceed a full red heat, or, say, $1000^{\circ}$ Cent., the protected. wire may be left permanently in the stove or furnace, whose temperature has to be recorded from time to time; but in measuring temperatures exceeding $1000^{\circ} \mathrm{Cent}$. , the tube is only exposed during a measured interval of, say, three minutes, to the heat, which time suffices for the thin protecting casing and the wire immediately exposed to its heated sides, to acquire within a determinable limit the temperature to be measured, but is not sufficient to soften the porcelain cylinder upon which the wire is wound. In this way temperatures exceeding the welding-point of iron, and approaching the melting-point of platinum, can be measured by the same instrument by which slight variations at ordinary temperatures are told. A thermometric scale is thus obtained embracing without a break the entire range.

The leading wires between the thermometric coil and the measuring instrument, which may be under certain circumstances several miles in length, would exercise a considerable disturbing influence if this were not eliminated by means of the third leading wire before mentioned, which is common to both bxanches of the measiring instrument.

Another source of error in the electrical pyrometer would arise through the porcelain cylinder npon which the wire is wound becoming conductive at very elevated temperatures; but it is shown that the error arising through this source is not of serious import.

The third part of the paper is descriptive of an instrument for measuring electrical resistance without the aid of a magnetic 